\title{
An Economical Method for Preparative Purification of Five Alkaloids from Coptis chinensis Franch by High-Speed Counter-Current Chromatography Using Singled Prepared Solvent System by GC
}

\author{
Lianhong Yin, Lina Xu, Xiaona Wang, Binan Lu, Yingnan Li, Mingming Hu, \\ Yuetao Liu, Jinyong Peng* \\ College of Pharmacy, Dalian Medical University, Dalian, China \\ E-mail: yinlianhong1015@163.com \\ Received August 8, 2010; revised February 22, 2011; accepted May 23, 2011
}

\begin{abstract}
Coptis chinensis Franch, a widely used Traditional Chinese Medicine, shows various kinds of bioactivity. The major active components of the herb are considered to be alkaloids. Thus, preparative separation of these alkaloids is critical important for further pharmacology and mechanism studies. In the paper, five alkaloids from $C$. chinensis were purified by HSCCC using the solvent system composed of chloroform-methanol-water $(2: 1: 1, \mathrm{v} / \mathrm{v} / \mathrm{v})$ single prepared. The content of each solvent in solvent system were determined by gas chromatography (GC), then according the ratios of solvents in each phase to prepare the mobile and stationary phase respectively. And a comparative study was carried out between together preparation and single preparation of the solvent system. The purities and recoveries of all the products were over $98.5 \%$ and $92 \%$. However, $134 \mathrm{~mL}$ chloroform, $336 \mathrm{~mL}$ methanol and $452 \mathrm{~mL}$ water were saved when the two phase were singled by GC. Our research showed an economical method for separating alkaloids from $C$. chinensis by HSCCC using the solvent system single prepared by GC.
\end{abstract}

Keywords: Alkaloid, Coptis chinensis Franch, High Speed Counter-Current Chromaotgraphy, Gas Chromatography, Solvent System

\section{Introduction}

Coptis chinensis Franch (Huanglian in Chinese), a famous traditional Chinese medicine in China, has been used for centuries to treat many kinds of disorders, such as dysentery, cholera, hypertension, leukemia, inflammation and lung disease [1-3]. The major bioactive components of the herb are considered to be alkaloids including palmatine, berberine, epiberberine, jatrorrhizine and coptisine [4]. Pharmacological studies and clinical practice have demonstrated that these alkaloids have antibacterial, anti-inflammatory, anticancer and anti-HIV effects [5-7]. Thus, preparative separation of the alkaloids from the $C$. chinensis is critical important for further pharmacology and mechanism studies. Some methods such as silica gel, polyamide, preparative RPLC and high-speed countercurrent chromatogramphy (HSCCC) have been reported previously. But the conventional column chromatogra- phy is tedious and requiring multiple chromatography steps, preparative RPLC have a smaller load ranges $[8,9]$. In addition, the adsorptions on stationary phase material and the solvents consume in both of two methods are serious. Thus, HSCCC as a good effective, high recovery and big load sample method is expected and used frequently to separate the alkaloids in recent years.

HSCCC, a unique continuous liquid-liquid partition chromatographic technique [10-12], allows directly introduction of crude samples into the column without pre-preparation, and yields a highly efficient separation in several hours, when sample load ranges from milligrams to kilograms $[13,14]$. It also can purify some compounds with an excellent sample recovery, which are having similar polarities $[15,16]$. As an efficient liquid chromatography preparative technique, HSCCC has a great potential for separation and purification of various 
natural products, and it has been widely used in many fields, such as plant activity constituents, ocean biologic activity constituents, antibiotic, polypeptides, protein and chiral components and so on [17-21].

Yang et al. [22] have used an optimum solvent system to separate four alkaloids including palmatine, berberine, epiberberine and coptisine from $C$. chinensis by preparative HSCCC, successfully. Peng et al. [23] also separated four alkaloids with high recoveries from $C$. chinensis by HSCCC with direct injection the powders of a raw materials without any preparation. It was not difficult to find that only four alkaloids were purified, and the purities of some products were not high enough. And for the long separation time, large amount of mobile phases were needed to finish the separations. Thus, a new condition of HSCCC and an economical method of single preparation of solvent system need to be developed for the five alkaloids separation from $C$. chinensis.

Selection of the solvent system is the most important factor for successful separation by HSCCC. We can select suitable solvent systems by looking at previous systems according to the chemical structures of the compounds using a literature search. We also can determine the partition coefficients $\left(K, K=C_{s} / C_{m}\right.$, where $C_{s}$ is the concentration of the sample in the stationary phase, and $C_{m}$ is the concentration in the mobile phase) of the chemicals, when the solvent system producing good $K$ values in the range of 0.5 to 2 can be selected. After selection suitable solvent system in general HSCCC procedure, the stationary and mobile phases of the solvent system are required to be prepared. The conventional method for preparation of the two-phase solvent system is as follows: according to the volume ratio of the selected solvent system, suitable volumes of the solvents are all added into a separated funnel and the mixture is thoroughly equilibrated at room temperature, and the upper and lower phases are separated shortly before use. In HSCCC, the volume of mobile phase required is according to the flow rate and separating time, and the use of stationary phase needed is only on basis of the HSCCC column size. Thus, when above preparation method is used, there will be much stationary phase is surplus, which is not only hostile to our environment protection, but also waste the resources.

The solvent system often used in HSCCC is composed of several kinds of organic solvents, so the composition of the upper and lower phases in solvent system can be analyzed by gas chromatography (GC) [24,25]. Thus, each layer could be prepared separately as required volume for minimizing solvent wastage [26]. In the present paper, the economical method was used for the single preparation of solvent system. Five alkaloids including palmatine, berberine, epiberberine, jatrorrhizine and coptisine (Figure 1) from $C$. chinensis were successfully purified by HSCCC with the suitable volume of the stationary and mobile phases single prepared by above economical method. And a comparison of the purities and recoveries of the products, separation time, and the use of the selected solvents with the HSCCC separation using the solvent system together prepared by conventional method was carried out. The advantage of our research was that an economical method was established for separating alkaloids from $C$. chinensis, more compounds were separated and more solvents were saved.

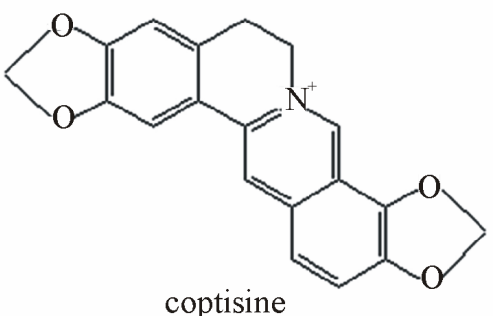<smiles>COc1cc2c(cc1OC)-c1cc3ccc4c(c3c[n+]1CC2)OCO4</smiles><smiles>COc1cc2c(cc1O)CC[n+]1cc3c(OC)c(OC)ccc3cc1-2</smiles><smiles>COc1ccc2cc3[n+](cc2c1OC)CCc1cc2c(cc1-3)OCO2</smiles><smiles>COc1cc2c(cc1OC)-c1cc3ccc(OC)c(OC)c3c[n+]1CC2</smiles>
palmatine

Figure 1. The chemical structures of the five alkaloids. 


\section{Experimental}

\subsection{Plant Materials and Chemicals}

C. chinensis was purchased from a local drug store (Dalian, China) and authenticated by Dr. Yunpeng Diao (Dalian Medical University, Dalian, China). The standards including palmatine, berberine, epiberberine, coptisine and jatrorrhizine were all purchased from the Chinese National Institute of Control of Pharmaceutical and Biological Products, Beijing, China.

Methanol used for HPLC was chromatographic grade (TEDIA, USA). Phosphoric acid and all other organic solvents used for sample preparation or HSCCC separation were analytical grade and purchased from ShenLian Chemical Factory (Shenyang, China). Reverse osmosis Milli-Q water (18 M $\Omega$ ) (Millipore, USA) was used for all solutions and dilutions.

\subsection{Apparatus}

The HSCCC instrument used in this study was a TBE-300A high-speed counter-current chromatograph (Shanghai Tauto Biotech Co., Ltd., Shanghai, China) with three multilayer coil separation columns connected in series (I.D. of the tubing $=1.6 \mathrm{~mm}$, total volume $=260$ $\mathrm{mL}$ ) and a $20 \mathrm{~mL}$ sample loop. The revolution radius or the distance between the holder axis and central axis of the centrifuge $(R)$ was $5 \mathrm{~cm}$, and the $\beta$ values of the multilayer coil varied from 0.5 at the internal terminal to 0.8 at the external terminal $(\beta=r / R$, where $\mathrm{r}$ is the distance from the coil to the holder shaft). The revolution speed of the instrument could be regulated with a speed controller in the range between 0 and $999 \mathrm{rpm}$. The HSCCC system was equipped with a model TBP-50A constant-flow pump (Shanghai Tauto Biological Company, China), a UV-Vis detector (Model UV-8823B, Beijing, China), and a model N2000 workstation (Zhejiang University, Hangzhou, China). The experimental temperature was adjusted by HX 1050 constant temperature circulating implement (Beijing Boyikang Lab Implement, Beijing, China).

The HPLC analyses were performed on an Agilent 1200 system (Agilent Technologies, Waldbronn, Germany), equipped with 1322A online vacuum degasser, G1311A quaternary pump, G1329A autosampler, G1314B UV detector and Chemstation software (Agilent technologies).

The solvent analysis was carried out with GC-14C (SHIMADZU, Japan) equipped with FID detector and a capillary column $(30 \mathrm{~m} \times 0.32 \mathrm{~mm}$, i.d. $0.25 \mu \mathrm{m}$ film thickness).

\subsection{Preparation of the Crude Extracts and Sample Solution}

The pulverized plant material of $800 \mathrm{~g}$ was extracted three times with $70 \%$ aqueous ethanol (solvent: sample ratio $=10: 1, \mathrm{v} / \mathrm{w})$ under reflux and $4 \mathrm{~h}$ for each. The filtrate was collected and evaporated under reduced pressure at $60^{\circ} \mathrm{C}$, and the residue was obtained. Then, the residue was re-dissolved in water, which was adjusted to $\mathrm{pH} 2.0$ by hydrogen chloride and stayed for one night. After that, the solution was filtered and the $\mathrm{pH}$ value was adjusted 10.0 with $\mathrm{NaOH}$ solution. Subsequently, the solution was extracted by chloroform, and the underlayer was separated and evaporated under reduced pressure at $40^{\circ} \mathrm{C}$ to dryness. Deep yellow power was produced, which was lyophilized and stored in a refrigerator for further HSCCC isolation.

The sample solution was prepared by dissolving 300 mg crude extract in $20 \mathrm{~mL}$ of the solvent mixture consisting of equal volumes of stationary and mobile phases single or together prepared of the solvent system composed of chloroform-methanol-water $(2: 1: 1, \mathrm{v} / \mathrm{v} / \mathrm{v})$.

\subsection{The Single Preparation of two-Phase Solvent System used in HSCCC}

In this study, we applied GC to single prepare the stationary and mobile phases of the solvent system used in HSCCC. The stationary and mobile phases of the selected solvent system were first prepared together by the traditional method. Then the contents of chloroform and methanol in the two phases were analyzed by GC using $n$-butanol as the internal standard and acetone as the dissolvent.

In the paper, different internal standards, capillary columns and temperature programs were investigated to optimize GC chromatographic conditions. Finally, a good separation for peaks of chloroform, methanol and $n$-butanol was achieved when the separation carried out on the following conditions: GC equipped with FID detector and a capillary column $(30 \mathrm{~m} \times 0.32 \mathrm{~mm}$, i.d. 0.25 $\mu \mathrm{m}$ film thickness) was used; the column temperature was held at $30^{\circ} \mathrm{C}$ for $10 \mathrm{~min}$, and then programmed to $120^{\circ} \mathrm{C}$ at $10^{\circ} \mathrm{C} / \mathrm{min}$. The injector and detector temperatures were set at $150^{\circ} \mathrm{C}$ and $180^{\circ} \mathrm{C}$, respectively, and injections were made in the split mode with a split ratio 1 : 20. Nitrogen was used as the carrier gas. The contents of chloroform and methanol in the stationary and mobile phases were determined individually, and suitable volumes of each solvent were calculated for single preparation of the stationary and mobile phases.

First, the correlations between the volumes and the weights of the stationary and mobile phases of the se- 
lected solvent system were investigated, and we found that excellent calibration curves were existed. The linear ranges $(\mathrm{mL})$, regression equations $(Y=\mathrm{a} X+\mathrm{b})$ and $\mathrm{R}^{2}$ of each phase were obtained compared with their weights. For stationary phase, in the range of $8.7 \sim 400 \mathrm{~mL}, Y=$ $0.9262 X+0.1727\left(\mathrm{R}^{2}=0.9999\right)$; for mobile phase, in the range of $11.4 \sim 1500 \mathrm{~mL}, Y=1.3612 X+0.9451\left(\mathrm{R}^{2}=\right.$ $0.9999)$, in which $Y$ is the weight of stationary phase or mobile phase and $X$ means the volume of each phase.

In GC analysis, the standard solution containing chloroform, methanol and internal standard at the concentrations of $0.02942,0.01582$ and $0.04040 \mathrm{~g} / \mathrm{mL}$, respectively, was prepared, which was used for subsequent determination. Then, $20 \mathrm{~mL}$ stationary and mobile phases were measured with the weights of 18.6967 and 28.1691 $\mathrm{g}$, respectively, and dissolved in acetone to prepare sample solutions. The internal standard was also added to afford the concentration of $0.04040 \mathrm{~g} / \mathrm{mL}$. All the solutions mentioned above were analyzed by $\mathrm{GC}$, and the peak areas were recorded. The concentrations $(\mathrm{g} / \mathrm{mL})$ of chloroform and methanol in each phase were calculated according to the following formulae (1) and (2) [27]. Thus, the concentrations of chloroform and methanol were $0.03535 \mathrm{~g} / \mathrm{mL}$ and $0.41203 \mathrm{~g} / \mathrm{mL}$ in the stationary phase, and $1.28125 \mathrm{~g} / \mathrm{mL}$ and $0.09390 \mathrm{~g} / \mathrm{mL}$ in the mobile phase, respectively. So, according to the formula (3), the concentrations of water in the two phases were $0.48746 \mathrm{~g} / \mathrm{mL}$ and $0.03331 \mathrm{~g} / \mathrm{mL}$, respectively.

$$
\begin{gathered}
f_{a}=\frac{A_{S} / C_{S}}{A_{R} / C_{R}} \\
C_{X}=f_{a} \cdot \frac{A_{X}}{A_{S}^{\prime} / C_{S}^{\prime}}
\end{gathered}
$$

where, $f_{a}$ is the correction factor; $A_{S}$ is the peak area of internal standard; $A_{R}$ is the peak area of standard; $C_{S}$ is the concentration of internal standard; $C_{R}$ is the concentration of standard; $A_{X}$ is the peak area of analyte in test sample; $C_{X}$ is the concentration of analyte in test sample; $A_{S}^{\prime}$ and $C_{S}^{\prime}$ are the peak area and concentration of internal standard in the test sample.

$$
C_{W}=C_{T}-C_{C}-C_{M}
$$

where, $C_{W}$ is the concentration of water in one phase; $C_{T}$ is the density of one phase $(\mathrm{g} / \mathrm{ml}), C_{C}$ and $C_{M}$ are the concentrations of chloroform and methanol in one phase, respectively.

For the known density of each solvent, we can switch the concentration of each solvent $(\mathrm{g} / \mathrm{mL}) C_{X}$ to volume ratio $(\mathrm{mL} / \mathrm{mL}) T_{X}$. In stationary phase, the volume ratios of chloroform, methanol and water were 0.02403 , 0.52090 and $0.48746 \mathrm{~mL} / \mathrm{mL}$; and in mobile phase, the volume ratios were $0.87100,0.11870$ and 0.03331 $\mathrm{mL} / \mathrm{mL}$, respectively
Then, according to the formula (4), we can calculate the volumes of chloroform, methanol and water in the stationary and mobile phases.

$$
V_{X}=V \cdot T_{X}
$$

where, $V$ is the total volume of the stationary and mobile phases needed in HSCCC; $V_{X}$ is the volume of solvent needed to prepare the stationary or mobile phase.

\subsection{The Rraditional together Preparation of two-phase Solvent System used in HSCCC}

The HSCCC experiments were performed with a twophase solvent system composed of chloroform-methanol-water $(2: 1: 1, \mathrm{v} / \mathrm{v} / \mathrm{v})$. Two methods for preparation of the stationary and mobile phases were carried out. One, the stationary and mobile phases were prepared together by the conventional method. After thoroughly equilibrating, the two phases of the solvent mixtures in a separating funnel at room temperatures were separated shortly before use. The other, the stationary and mobile phases were single prepared, according to the results of GC analysis, namely $1102 \mathrm{~mL}$ chloroform, $150 \mathrm{~mL}$ methanol and $42 \mathrm{~mL}$ water were added together to prepare the mobile phase, and $6 \mathrm{~mL}$ chloroform, $135 \mathrm{~mL}$ methanol and $127 \mathrm{~mL}$ water were mixed to prepare the stationary phase.

\subsection{HSCCC Separation Procedure}

In each separation, the multiplayer coil column was first entirely filled with the upper phase as the stationary phase. Then the mobile phase was pumped into the 'head'-end of the HSCCC coil column at a suitable flow rate of $1.5 \mathrm{~mL} / \mathrm{min}$, while the HSCCC apparatus was rotated at a speed of $800 \mathrm{rpm}$. After a clear mobile phase was eluted from the tail outlet and the two phases had established a hydrodynamic equilibrium throughout the column, the sample solution was injected through the injection valve. The effluent from the outlet of the column was continuously monitored at $280 \mathrm{~nm}$ and each peak fraction was collected according to the elution profile. After the separation was completed, the centrifuge was stopped and retention of the stationary phase was measured by collecting the column contents by forcing them out of the column with pressurized gas.

\subsection{HPLC Analysis for Purity Determination}

In the present paper, the crude sample and each HSCCC peak fraction were all analyzed by HPLC. The analysis was carried out on an Agilent Eclipse Plus $\mathrm{C}_{18}(150 \mathrm{~mm}$ $\times 4.6 \mathrm{~mm}$, i.d., $5 \mu \mathrm{m}$ ), and the mobile phase composed of methanol (A)-3\% phosphoric acid (B) (pH 2.0, adjusted 
by triethylamine) with a gradient mode $(0 \sim 15 \mathrm{~min}$, $25 \% \mathrm{~A} \rightarrow 30 \% \mathrm{~A} ; 25 \sim 38 \mathrm{~min}, 30 \% \mathrm{~A} ; 38 \sim 60 \mathrm{~min}$, $30 \% \mathrm{~A} \rightarrow 35 \% \mathrm{~A})$. The flow rate was controlled at 0.8 $\mathrm{mL} / \mathrm{min}$, and the detection wavelength was selected at $270 \mathrm{~nm}$.

\subsection{Chemical Structure Identification and Confirmation}

Identification of the HSCCC peak fractions was carried out by MS (API 3200 mass spectrometer, Applied Biosystems, USA), UV spectra (U-3010 UV, Hitachi, Japan), and the standards.

\section{Results and Discussion}

\subsection{Optimization Suitable HPLC Analytical Conditions}

A sensitive method for determination of the alkaloids in crude extract of $C$. chinensis is a prerequisite to the HSCCC separation. In recent years, many methods have been developed to detect the alkaloids in C. chinensis, such as capillary electrophoresis (CE), LC-MS and LC-MS-MS [28-34]. Among them, CE analysis is high sensitive and excellent, but the pre-condition and background solution are complex, and the technique can not be controlled easily. LC-MS and LC-MS-MS technique are fast, sensitive and accurate, but the apparatus is too expensive and not all research departments can afford it. By now, there are many HPLC analytical methods have been reported to determine alkaloids in C. chinensis $[35,36]$. However, we can easily find that some flaws were existed in reported papers including long separation time, not good separation, complex mobile phase and the limited number of detected compounds. In the present paper, different chromatographic column packed with different materials purchased from different companies, mobile phases composed of acetonitrile-water and methanol-water with some modifiers including phosphoric buffer, acetic acid, formic acid, phosphoric acid, formic acid adjusted by ammonia or by triethylamine with different $\mathrm{pH}$ values, and different gradient elution modes were all investigated. Good separation was achieved when the process was carried out on an Agilent Eclipse Plus $\mathrm{C}_{18}(150 \mathrm{~mm} \times 4.6 \mathrm{~mm}$, i.d., $5 \mu \mathrm{m})$, and the mobile phase composed of methanol (A)-3\% phosphoric acid (B) ( $\mathrm{pH} 2.0$, adjusted by triethylamine) with a gradient elution mode $(0 \sim 15 \mathrm{~min}, 25 \% \mathrm{~A} \rightarrow 30 \% \mathrm{~A} ; 25 \sim 38 \mathrm{~min}$, $30 \% \mathrm{~A} ; 38 \sim 60 \mathrm{~min}, 30 \% \mathrm{~A} \rightarrow 35 \% \mathrm{~A})$. The detection wavelength was selected at $270 \mathrm{~nm}$ and the flow rate was controlled at $0.8 \mathrm{~mL} / \mathrm{min}$. On the optimized conditions, the beautiful chromatograms of crude sample and mixed standards are shown in Figure 2(a) and Figure 2(b), in which the peaks 1, 2, 3, 4 and 5 correspond to coptisine, epiberberine, jatrorrhizine, berberine and palmatine, respectively. The advantage of the method was that the mobile phase was simple and no salt or buffer was needed. The separated time was mediate, and all the alkaloids were separated fully.

\subsection{Optimization of HSCCC Conditions}

According to HPLC analysis shown in Figure 2(a), there are five major components in the crude extract of $C$. chinensis. Many papers have been reported to separate alkaloids from this plant by HSCCC $[22,23]$. The solvent system composed of chloroform-methanol-water is considered to be one of the classical solvent systems in alkaloids purification, but the ratios between the solvents were not invariable. The crude extracts of Sophora flavescens Ait. were separated and purified by high-speed counter-current chromatography (HSCCC) with a twophase solvent system composed of chloroform-methanol-2.3 × $10^{-2} \mathrm{M} \mathrm{NaH}_{2} \mathrm{PO}_{4}(27.5: 20: 12.5, \mathrm{v} / \mathrm{v} / \mathrm{v})$ [37], and the optimum solvent systems $\mathrm{CHCl}_{3}-\mathrm{MeOH}-0.3$ $\mathrm{M} / 0.2 \mathrm{M} \mathrm{HCl}(4: 1.5: 2, \mathrm{v} / \mathrm{v} / \mathrm{v})$ were used to separate lappaconitine, ranaconitine, $N$-deacetyllappaconitine and $\mathrm{N}$-deacetylranaconitine from Aconitum sinomontanum Nakai [38]. So, in our research, the solvent systems composed of chloroform-methanol-water at the volume ratios of 4:3:2(v/v/v) and 2:1:1 (v/v/v) and chloroform-ethanol-water at the volume ratios of $4: 3: 2(\mathrm{v} / \mathrm{v} / \mathrm{v})$ and $2: 1: 1$ $(\mathrm{v} / \mathrm{v} / \mathrm{v})$ were further optimized. The stationary and mobile phases of those four kinds of solvent systems were all prepared by together and single preparation methods, and the K-values of five compounds were determined. The results are listed in Table 1. It was obvious that the K-values of the compounds epiberberine, coptisine and jatrorrhizine, and the compounds palmatine and berberine had no difference when the solvent system composed of chloroform-ethanol-water $(2: 1: 1, \mathrm{v} / \mathrm{v} / \mathrm{v})$ was used as the two-phase solvent system in spite of the methods of preparation. When chloroform-ethanol-water $(4: 3: 2$, $\mathrm{v} / \mathrm{v} / \mathrm{v})$ or chloroform-methanol-water $(4: 3: 2, \mathrm{v} / \mathrm{v} / \mathrm{v})$ were used as the separation systems, the targets could not be well separated and the purities of the compounds were not satisfactory. Thus, they were not suitable for HSCCC separation of the five alkaloids from the crude extract of C. chinensis. The other solvent system tested in present study was chloroform-methanol-water $(2: 1: 1, \mathrm{v} / \mathrm{v} / \mathrm{v})$, and suitable K-values were produced not only in condition of together preparation of the stationary and mobile phases, but also in condition of single preparation method. Thus, the solvent system composed of chloroform-methanolwater $(2: 1: 1, \mathrm{v} / \mathrm{v} / \mathrm{v})$ was selected to purify the targets 


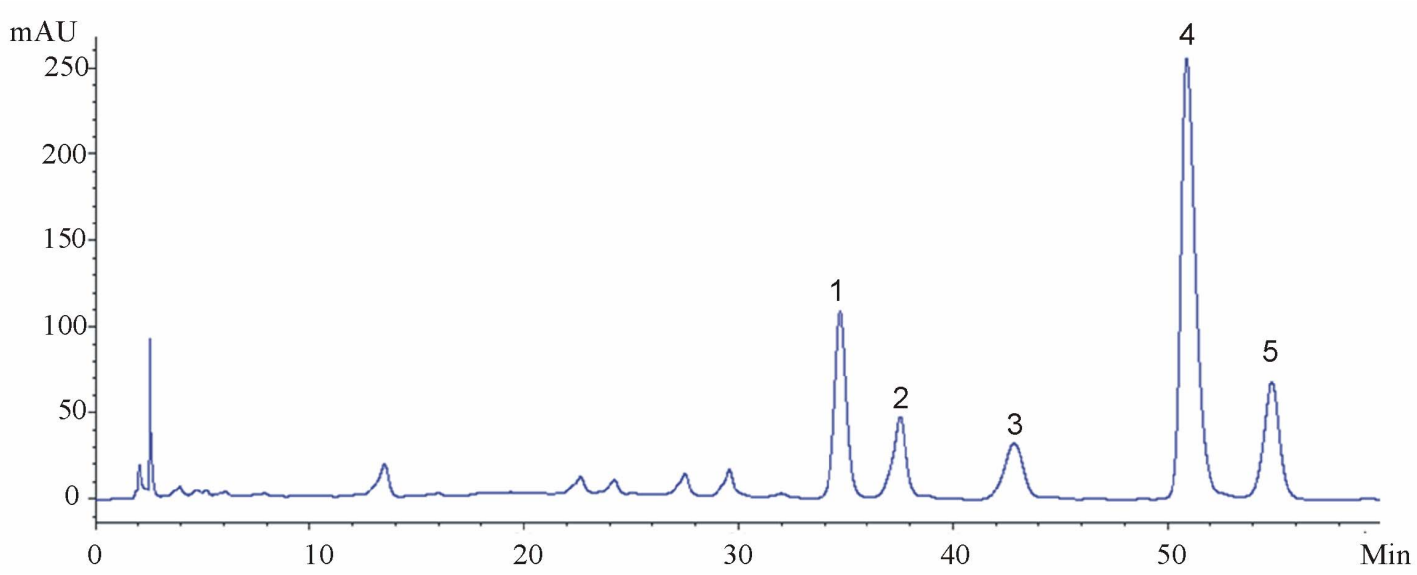

(a)

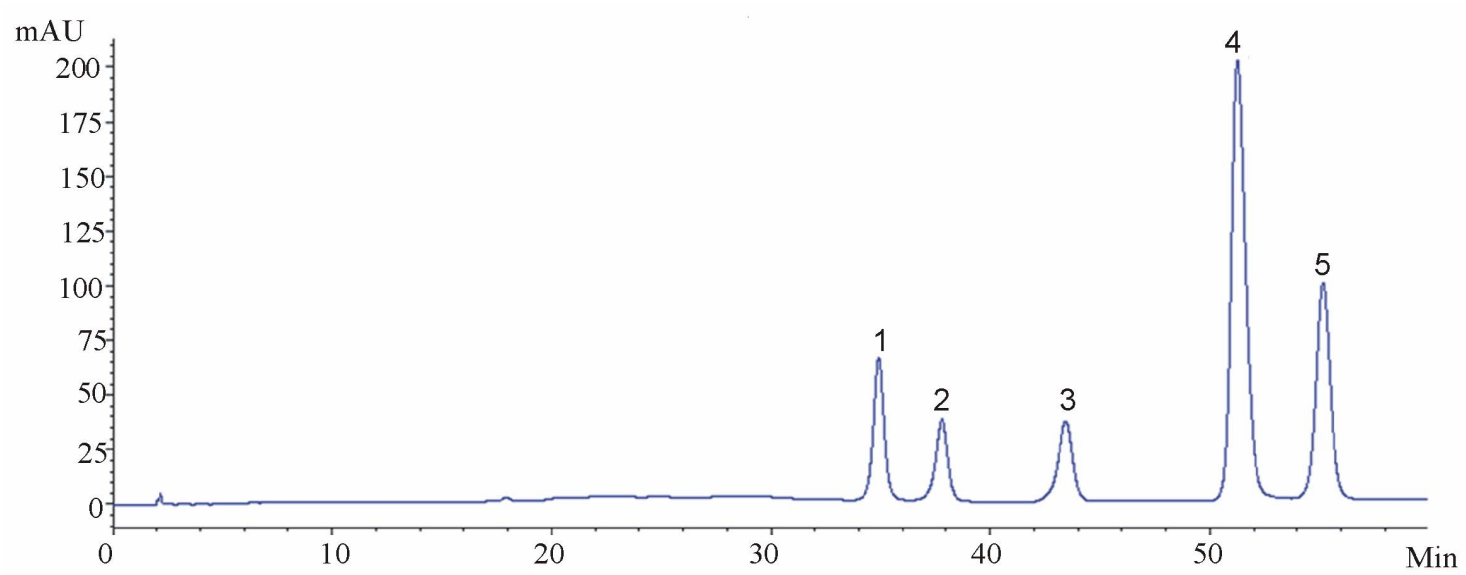

(b)

Figure 2. The HPLC chromatograms of the crude sample from $C$. chinensis Franch and the standards. (a) The crude extract; (b) The mixed standards. Peak 1, 2, 3, 4 and 5 correspond to coptisine, epiberberine, jatrorrhizine, berberine, and palmatine, respectively.

Table 1. The K-values of the targets in different solvent systems together or single prepared.

\begin{tabular}{ccccccc}
\hline \multirow{2}{*}{ Solvent system (v/v) } & $\begin{array}{c}\text { Preparation } \\
\text { method }\end{array}$ & Coptisine & Epiberberine & Jatrorrhizine & Berberine & Palmatine \\
\cline { 3 - 7 } & $1^{a}$ & 2.60 & 2.16 & 4.53 & 1.48 & 0.97 \\
Chloroform-methanol-water & $2^{b}$ & 2.44 & 1.95 & 4.29 & 1.83 & 1.28 \\
$\begin{array}{c}\text { (2:1:1) } \\
\text { Chloroform-methanol-water }\end{array}$ & 1 & 3.00 & 2.36 & 2.52 & 1.93 & 1.36 \\
$(4: 3: 2)$ & 2 & 1.98 & 1.39 & 1.89 & 1.08 & 0.84 \\
Chloroform-ethanol-water & 1 & 1.42 & 1.30 & 1.32 & 0.71 & 0.67 \\
$(2: 1: 1)$ & 2 & 1.24 & 1.15 & 1.23 & 0.65 & 0.63 \\
Chloroform-ethanol-water & 1 & 2.14 & 1.89 & 2.02 & 1.24 & 1.05 \\
$(4: 3: 2)$ & 2 & 2.63 & 2.45 & 2.03 & 1.51 & 1.30 \\
\hline
\end{tabular}

${ }^{a} \overline{\text { Together preparation of the stationary and mobile phases; }}{ }^{b} \overline{\text { Single preparation of the stationary and mobile phases. }}$

from the crude extract of $C$. chinensis.

Other HSCCC conditions, such as flow rate of mobile phase, separation temperature and revolution speed, were also important for a successful HSCCC separation. The flow rate of the mobile phase determines the separation time, the amount of stationary phase retained in the col- 
umn, and therefore the peak resolution. The different temperatures may cause different retentions of the stationary phases, and the speed may produce the volume of the stationary phase retained leading to lower peak resolution or excessive sample band broadening by violent pulsation of the column. So, different flow rates of the mobile phase, different temperatures and different revolution speeds were investigated. Finally, we found that the flow rate of mobile phase set at $1.5 \mathrm{~mL} / \mathrm{min}$, the temperature sated at $30^{\circ} \mathrm{C}$, and the apparatus rotated at $800 \mathrm{rpm}$ were the best conditions for this HSCCC separation.

Under the optimized conditions, the crude extract was successfully separated by HSCCC using the solvent system composed of chloroform-methanol-water (2:1:1, $\mathrm{v} / \mathrm{v} / \mathrm{v}$ ). Figure 3(a) shows the chromatogram of the crude extract purified by HSCCC when the stationary and mobile phases of the solvent system were single prepared, and Figure 3(b) shows the chromatogram of the crude extract isolated by HSCCC when the stationary and mobile phases of the solvent system were together prepared. Five fractions ( I, II, III, IV and V) were collected according to the profiles shown in Figure 3(a) and Figure 3(b), respectively.

\subsection{Purity and Recovery Retermination}

The obtained fractions from HSCCC were all analyzed by HPLC compared with the standards for purity determination. The outcomes of the contents of the five alkaloids in crude sample, the purity, and recovery of the obtained targets are listed in Table 2. It was obvious that, in the separation performed by HSCCC using single prepared stationary and mobile phases, the purities and recoveries of the five alkaloids were over $98 \%$ and $92 \%$, respectively. In the process performed by HSCCC using together prepared stationary and mobile phases, the purities and recoveries of the products had no differences compared with single preparation method. Namely, the purities and recoveries of the obtained compounds were good, no matter which preparation method of solvent system were used.

\subsection{Chemical Structure Identification}

The obtained fractions I, II, III, IV and Vwere identified by MS, UV and the standards. The retention times of the separated compounds were the same compared with the standards. The MS and UV spectra data are agreement with those in the literature [4]. Thus, the obtained fractions I, II, III, IV and V were identified to be palmatine, berberine, epiberberine, coptisine and jatrorrhizine, respectively.

\subsection{Comparison Study of Single and Together Preparation of the Stationary and Mobile Phases}

Through the HSCCC chromatograms and HPLC analysis, we can easily find that there was no difference between the stationary and mobile phases of the selected solvent system prepared together and single. In HSCCC separation using single prepared stationary and mobile phases, the retention of the stationary phase was $70 \%$, and the separation time was $800 \mathrm{~min}$ and total of $1265 \mathrm{~mL}$ of the mobile phase was required, which was calculated as the following formula (5), and $260 \mathrm{~mL}$ stationary phase was required only on basis of the HSCCC column size.

$$
V_{t m p}=V_{1}+V_{2}
$$

where $V_{\text {tmp }}$ means the total volume of the mobile phase required in HSCCC separation; $V_{1}$ is the volume of the stationary phase eluted out from the column for hydrodynamic equilibrium, and $V_{2}$ is the use of the mobile phase to elute the targets, which was calculated according to the formula (6), where $T_{M}$ is separation time and $F_{M}$ is the flow rate of the mobile phase.

$$
V_{2}=T_{M} \times F_{M}
$$

The compositions of the mobile phase and stationary phase were analyzed by GC to calculate the solvent consume. According to the volume of each phase used, the solvent used in the procedure was obtained. Thus, total of $1108 \mathrm{~mL}$ chloroform, $285 \mathrm{~mL}$ methanol and $169 \mathrm{~mL}$ water were needed in HSCCC procedure with single preparation method.

In the separation procedure using together prepared stationary and mobile phases, the retention of the stationary phase was $77 \%$, and the separation time was 820 min, and total of $1290 \mathrm{~mL}$ mobile phase was needed, which was also calculated with the formulae (5) and (6). $260 \mathrm{~mL}$ stationary phase was also required. The solvent system composed of chloroform-methanol-water (2:1:1, $\mathrm{v} / \mathrm{v} / \mathrm{v}$ ) was accurately prepared to obtain the required mobile and stationary phases. There were three calibration curves established to describe the correlations between the use of the mobile phase with chloroform, methanol and water volumes. The linearity of the solvent volume $(X, \mathrm{~mL})$ and the mobile phase volume $(Y, \mathrm{~mL})$ was investigated in the range of $15-1500 \mathrm{~mL}$. $Y=$ $1.0372 X+1.6264\left(\mathrm{R}^{2}=0.9999\right.$, for chloroform $) ; Y=$ $2.0743 X+1.6264\left(\mathrm{R}^{2}=0.9999\right.$, for methanol $) ; Y=$ $2.0743 X+1.6264\left(\mathrm{R}^{2}=0.9999\right.$, for water $)$. Thus, 1242 $\mathrm{mL}$ chloroform, $621 \mathrm{~mL}$ methanol and $621 \mathrm{~mL}$ water were required to prepare the solvent system according to the calibration curves, when the stationary and mobile phases were prepared together.

Thus, $134 \mathrm{~mL}$ chloroform, $336 \mathrm{~mL}$ methanol and 452 

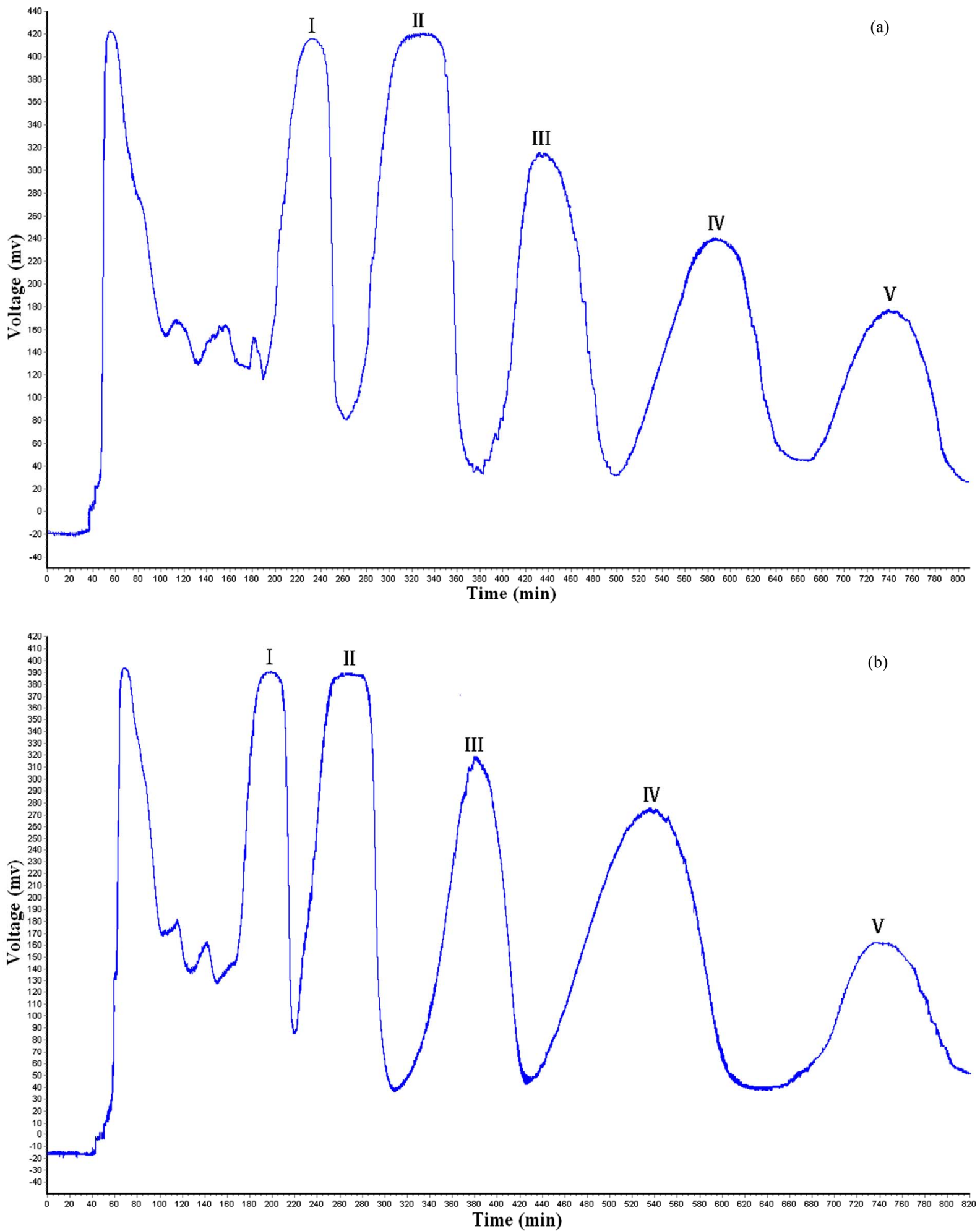

Figure 3. The HSCCC chromatograms of the crude extract from $C$. chinensis Franch. HSCCC conditions: Two-phase solvent system: Chloroform-methanol-water (2:1:1, v/v/v); flow rate: $1.5 \mathrm{~mL} / \mathrm{min}$; revolution speed: $800 \mathrm{rpm}$; detection wavelength: $280 \mathrm{~nm}$; sample size: $300 \mathrm{mg}$; separation temperature: $30^{\circ} \mathrm{C}$. I , II, III, IV and V are the collected fractions. (a) the stationary and mobile phases are single prepared by GC; (b) the stationary and mobile phases are together prepared by the conventional method. 
Table 2. The detailed information for separating the five alkaloids from C. chinensis Franch by HSCCC using different solvent system preparation methods.

\begin{tabular}{|c|c|c|c|c|c|c|c|}
\hline \multirow{2}{*}{ Compound } & \multirow{2}{*}{ Content $^{a}$} & \multicolumn{3}{|c|}{ Together preparation method } & \multicolumn{3}{|c|}{ Single preparation method } \\
\hline & & Amount $^{b}$ & Recovery $^{c}$ & Purity & Amount & Recovery & Purity \\
\hline Palmatine & $7.42 \%$ & $20.8 \mathrm{mg}$ & $92.07 \%$ & $98.53 \%$ & $21.3 \mathrm{mg}$ & $95.13 \%$ & $99.42 \%$ \\
\hline Berberine & $13.00 \%$ & $38.1 \mathrm{mg}$ & $96.00 \%$ & $98.27 \%$ & $37.4 \mathrm{mg}$ & $95.51 \%$ & $99.60 \%$ \\
\hline Epiberberine & $5.70 \%$ & $16.3 \mathrm{mg}$ & $94.05 \%$ & $98.67 \%$ & $16.4 \mathrm{mg}$ & $94.71 \%$ & $98.75 \%$ \\
\hline Coptisine & $8.84 \%$ & $25.4 \mathrm{mg}$ & $95.12 \%$ & $99.31 \%$ & $25.1 \mathrm{mg}$ & $93.81 \%$ & $99.12 \%$ \\
\hline Jatrorrhizine & $1.31 \%$ & $3.7 \mathrm{mg}$ & $93.98 \%$ & $99.82 \%$ & $3.7 \mathrm{mg}$ & $93.50 \%$ & $99.31 \%$ \\
\hline
\end{tabular}

${ }^{a}$ The content of the component in the crude extract of $C$. chinensis Franch; ${ }^{b}$ The amount of the component separated by HSCCC;

${ }^{c} \operatorname{Recov} \operatorname{ery}(\%)=\left(\frac{P 2 \times W 2}{P 1 \times W 1}\right) \times 100 \%$. Where $P 1$ is the content of the compound in crude sample; $W 1$ is the amount of the crude sample for

HSCCC isolation; $P 2$ is the purity of the obtained compound; $W 2$ is the amount of the obtained compound from HSCCC. $P 1$ and $P 2$ were calculated by external standard method of HPLC.

Table 3. The details of the HSCCC separation with different preparative methods and the expenditures of the three solvents.

\begin{tabular}{|c|c|c|c|c|c|c|c|c|}
\hline $\begin{array}{c}\text { Preparation } \\
\text { method }^{a}\end{array}$ & $\begin{array}{l}\text { Retention of the } \\
\text { stationary phase }\end{array}$ & $\begin{array}{c}\text { Separation } \\
\text { time }\end{array}$ & $\begin{array}{c}\text { Stationary phase } \\
\text { required }^{b}\end{array}$ & $\begin{array}{c}\text { Mobile phase } \\
\text { required }^{c}\end{array}$ & $\begin{array}{c}\text { Required of the } \\
\text { two phases }\end{array}$ & Chloroform & Methanol & Water \\
\hline \multirow{3}{*}{$\begin{array}{c}\text { Together } \\
\text { preparation }\end{array}$} & \multirow{3}{*}{$77 \%$} & \multirow{3}{*}{$820 \mathrm{~min}$} & \multirow{3}{*}{$260 \mathrm{~mL}$} & \multirow{3}{*}{$1290 \mathrm{~mL}$} & Mobile phase $\left(V_{m 1}\right)$ & $1242 \mathrm{~mL}$ & $621 \mathrm{~mL}$ & $621 \mathrm{~mL}$ \\
\hline & & & & & Stationary phase $^{d}\left(V_{s 1}\right)$ & $0 \mathrm{~mL}$ & $0 \mathrm{~mL}$ & $0 \mathrm{~mL}$ \\
\hline & & & & & $\begin{array}{c}\text { Total volume } \\
\left(V_{t 1}=V_{m 1}+V_{s 1}\right)\end{array}$ & $1242 \mathrm{~mL}$ & $621 \mathrm{~mL}$ & $621 \mathrm{~mL}$ \\
\hline \multirow{4}{*}{$\begin{array}{l}\text { Single prepa- } \\
\text { ration }\end{array}$} & \multirow{4}{*}{$75 \%$} & \multirow{4}{*}{$800 \mathrm{~min}$} & \multirow{4}{*}{$260 \mathrm{~mL}$} & \multirow{4}{*}{$1265 \mathrm{~mL}$} & Mobile phase $\left(V_{m 2}\right)$ & $1102 \mathrm{~mL}$ & $150 \mathrm{~mL}$ & $42 \mathrm{~mL}$ \\
\hline & & & & & Stationary phase $\left(V_{s 2}\right)$ & $6 \mathrm{~mL}$ & $135 \mathrm{~mL}$ & $127 \mathrm{~mL}$ \\
\hline & & & & & $\begin{array}{c}\text { Total volume } \\
\left(V_{t 2}=V_{m 2}+V_{s 2}\right)\end{array}$ & $1108 \mathrm{~mL}$ & $285 \mathrm{~mL}$ & $169 \mathrm{~mL}$ \\
\hline & & & & & $\begin{array}{l}\text { Saved reagent } \\
\left(V_{S}=V_{t 1}-V_{t 2}\right)\end{array}$ & $134 \mathrm{~mL}$ & $336 \mathrm{~mL}$ & $452 \mathrm{~mL}$ \\
\hline
\end{tabular}

${ }^{a}$ The Preparation method means the method to prepare the stationary and mobile phases in HSCCC process; ${ }^{b}$ The use of the stationary phase in HSCCC is the column volume of the apparatus; ${ }^{c}$ The use of the mobile phase in HSCCC process is calculated according to the flow rate of the mobile phase and the separation time; ${ }^{d}$ The stationary phase and mobile phase are prepared together.

$\mathrm{mL}$ water were saved when the stationary and mobile phases were single prepared in HSCCC purification. All the details are shown in Table 3.

\section{Conclusions}

In this paper, five alkaloids from $C$. chinensis were successfully separated by HSCCC using the solvent system composed of chloroform-methanol-water $(2: 1: 1, \mathrm{v} / \mathrm{v} / \mathrm{v})$, of which the stationary and mobile phases were singled prepared by GC. The results indicated that the method for the alkaloids separation is applied, and the single preparation technique of the two phases by GC in HSCCC was efficient and solvent saving. And an economical method was established for separating alkaloids from $C$. chinensis. The single preparation of solvent system by GC might be widely used in long time HSCCC separation and purification.

\section{Acknowledgements}

This research was partially supported by the Key Labo- ratory of Liaoning University (No. 2008S072), Liaoning, China.

\section{References}

[1] H. H. Yu, K. J. Kim, J. D. Cha, H. K. Kim, Y. E. Lee, N. Y. Choi and Y. O. You, "Antimicrobial Activity of Berberine Alone and in Combination with Ampicillin or Oxacillin against Methicillin-Resistant Staphylococcus Aureus," Journal of Medicial Food, Vol. 8, No. 4, 2005, pp. 454-461. doi:10.1089/jmf.2005.8.454

[2] H. A. Jung., N. Y. Yoon, H. J. Bae, B. S. Min and J. S. Choi, "Ingibitory Activities of the Alkaloids from Coptidis Rhizoma against Aldose Reductase," Archives of Pharmacal Research, Vol. 31, No. 11, 2008, pp. 14051412. doi:10.1007/s12272-001-2124-Z

[3] J. Liu, C. He, K. Zhou, J. Wang and J. X. Kang, "Coptis Extracts Enhance the Anticancer Effect of Estrogen Receptor Antagonists on Human Breast Cancer Cells," Biochemical and Biophysical Research Communications, Vol. 378, No. 2, 2009, pp. 174-178. doi:10.1016/j.bbrc.2008.10.169

[4] J. H. Chen, F. M. Wang, J. Liu, F. S. C. Lee, X. R. Wang and H. G. Yang, "Analysis of Alkaloids in Coptis 
Chinensis Franch by Accelerated Solvent Extraction Combined with Ultra Performance Liquid Chromatographic Analysis with Photodiode Array and Tandem Mass Spectrometry Detections," Analytia Chimuca Acta, Vol. 613, No. 2, 2008, pp. 184-195. doi:10.1016/j.aca.2008.02.060

[5] H. L. Yang, S. S. Yu and Y. H. Pei, "Studies on Chemical Constituents from leaves of Lysidice Brevicalyx," Zhongguo Zhong Yao Za Zhi, Vol. 33, No. 22, 2008, pp. 26332635.

[6] C. L. Kuo, C. W. Chi and T. Y. Liu, "The Anti-Infammatory Potential of Berberine in Vitro and in Vivo," Cancer Letter, Vol. 203, No. 2, 2004, pp. 127-137. doi:10.1016/j.canlet.2003.09.002

[7] L. Q. Tang, W. Wei, L. M. Chen and S. Liu, "Effects of Berberine on Diabetes Induced by Alloxan and a HighFat/High-Cholesterol Diet in Rats," Journal of Ethnopharmacology, Vol. 108, No. 1, 2006, pp. 109-115. doi:10.1016/j.jep.2006.04.019

[8] L. P. Qu, G. R. Fan, J. Y. Peng and H. M. Mi, "Isolation of Six Isoflavones from Semen Sojae Praeparatum by Preparative HPLC," Fitoterapia, Vol. 78, No. 3, 2007, pp. 200-204. doi:10.1016/j.fitote.2006.11.002

[9] Y. Q. Yin, Z. B. Shen and L. Y. Kong, "Studies on Chemical Constituents from Ipomoea Batatas," Lishizhen Medicine and Materia Medica Research, Vol. 19, No. 11, 2008, pp. 1501-1503.

[10] Y. Ito and R. L. Bowman, "Counter-Current Chromatography: Liquid-Liquid Partition Chromatography without Solid Support," Science, Vol. 167, No. 3916, 1970, pp. 281-283. doi:10.1126/science.167.3916.281

[11] Y. Ito, J. L. Sandlin and W. G. Bowers, "High-Speed Preparative Counter Current Chromatography with a Coil Planet Centrifuge," Journal of Chromatography, Vol. 244, 1982, pp. 247-258. doi:10.1016/S0021-9673(00)85688-5

[12] Y. Ito, "Counter Current Chromatography: Theory and Practice," Marcel Dekker, New York, 1988, pp. 79-442.

[13] Y. Ma, Y. Ito and A. Foucault, "Resolution of Gram Quantities of Racemates by High-Speed Counter-Current Chromatography," Journal of Chromatography A, Vol. 704, No. 1, 1995, pp. 75-81. doi:10.1016/0021-9673(95)00148-G

[14] L. J. Chen, Q. Zhang, G. L. Yang, L. Y. Fan, J. Tang, I. Garrard, S. N. Ignatova, D. Fisher and I. A. Sutherland. "Rapid Purification and Scale-up of Honokiol and Magnolol Using High-Capacity High-Speed Counter-Current Chromatography," Journal of Chromatography A, Vol. 1142 , No. 2, 2007, pp. 115-122. doi:10.1016/i.chroma.2006.09.098

[15] D. S. Abrams and J. M. Prausnitz, "Statistical Thermodynamics of Liquid Mixtures: A New Expression for the Excess Gibbs Free Energy of Partly or Completely Miscible Systems," AIChE Journal, Vol. 21, 1975, pp. 116128. doi:10.1002/aic.690210115

[16] S. Y. Shi, K. L. Huang, Y. P. Zhang and S. Liu, "Preparative Isolation and Purification of Two Flavonoid Glycosides from Taraxacum Mongolicum by High-Speed
Counter-Current Chromatography," Separation and purification technology, Vol. 60, No. 1, 2008, pp. 81-85. doi:10.1016/j.seppur.2007.07.047

[17] J. Y. Peng, G. R. Fan, L. P. Qu, Z. Xin and Y. T. Wu, "Application of Preparative High-Speed Counter-Current Chromatography for Isolation and Separation of Schizandrin and Gomisin A from Schisandra Chinensis," Journal of Chromatography A, Vol. 1082, No. 2, 2005, pp. 203207. doi:10.1016/j.chroma.2005.05.091

[18] H. B. Li, F. Chen, T. Y. Zhang, F. Q. Yang and G. Q. Xu, "Preparative Isolation and Purification of Lutein from the Microalga Chlorella vulgaris by High-Speed CounterCurrent Chromatography," Journal of Chromatography A, Vol. 905, No. 1-2, 2001, pp. 151-155. doi:10.1016/S0021-9673(00)00987-0

[19] C. Seger, K. Eberhart, S. Sturm, H. Strasser and H. Stuppner, "Apolar Chromatography on Sephadex LH-20 Combined with High-Speed Counter-Current Chromatography: High Yield Strategy for Structurally Closely Related an Analyses-Destruxin Derivatives from Metarhizium anisopliae as a Case Study," Journal of Chromatography A, Vol. 1117, No. 1, 2006, pp. 67-73. doi:10.1016/j.chroma.2006.03.055

[20] W. B. Zhi, Q. Y. Deng, J. N. Song, M. Gu and F. Ouyang, "One-Step Purification of Alphamylase from the Cultivation Supernatant of Recombinant Bacillus Subtilis by High-Speed Counter-Current Chromatography with Aqueous Polymer Two-Phase Systems," Journal of Chromatography A, Vol. 1070, No. 1-2, 2005, pp. 215219. doi:10.1016/j.chroma.2005.02.065

[21] E. Pérez, M. J. Santos and C. Minguillón, "Application of Cellulose and Amylose Arylcarbamates as Chiral Selectors in Counter-Current Chromatography," Journal of Chromatography A, Vol. 1107, No. 1-2, 2006, pp. 165174. doi:10.1016/j.chroma.2005.12.061

[22] F. Q. Yang, T. Y. Zhang, R. Zhang and Y. Ito, “Application of Analytical and Preparative High-Speed CounterCurrent Chromatography for Separation of Alkaloids from Coptis chinensis Franch," Journal of Chromatography $A$, Vol. 829, No.1-2, 1998, pp. 137-141. doi:10.1016/S0021-9673(98)00776-6

[23] J. Y. Peng, X. Han, Y. W. Xu, Y. Qi, L. N. Xu and Q. W. $\mathrm{Xu}$, "New Approach of Application High Speed Countercurrent Chromatography Coupled with Direct Injection the Powders of a Raw Materials without Any Preparation, for Isolation and Separation of Four Alkaloids with High Recoveries from Coptis chinensis Franch," Journal of Liquid Chromatography \& Related Technologies, Vol. 30, No. 17-20, 2007, pp. 2929-2940. doi:10.1080/10826070701588984

[24] P. Jacobs, W. Dewé, A. Flament, M. Gibella and A. Ceccato, "A New Validation Approach Applied to the GC Determination of Impurities in Organic Solvents," Journal of Pharmaceutical and Biomedical Analysis, Vol. 40,No. 2, 2006, pp. 294-304. doi:10.1016/j.jpba.2005.06.036

[25] F. J. Arrebola, M. J. González-Rodríguez, A. Garrido Frenich, A. Marín-Juan and J. L. Martínez Vidal, "Determination of Halogenated Solvents Content in Olive Oil 
by Two Completely Automated Headspace Techniques Coupled to Gas Chromatography-Mass Spectrometry," Analytica Chimica Acta, Vol. 552, No. 1-2, 2005, pp. 6066. doi:10.1016/j.aca.2005.07.054

[26] I. J. Garrard, L. Janaway and D. Fisher, "Minimising Solvent Usage in High Speed, High Loading, and High Resolution Isocratic Dynamic Extraction," Journal of Liquid Chromatography \& Related Technologies, Vol. 30, No. 1-4, 2007, pp. 151-163. doi:10.1080/10826070601077252

[27] W. Y. Liu, "Pharmaceutical Analysis," People's Medical Publishing House, 2006, pp. 75-80.

[28] Y. M. Liu and S. J. Shen, "Determination of Coptisine, Berberine and Palmatine in Traditional Chinese Medicinal Preparations by Capillary Electrophoresis," Journal of Chromatography A, Vol. 639, No. 2, 1993, pp. 323-328. doi:10.1016/0021-9673(93)80269-E

[29] S. W. Sun and H. M. Tseng, "Improved Detection of Coptidis Alkaloids by Field-Amplified Sample Stacking in Capillary Electrophoresis," Journal of Pharmaceutical and Biomedical Analysis, Vol. 36, No. 1, 2004, pp. 43-48. doi:10.1016/j.jpba.2004.04.017

[30] S. Yu, X. Y. Pang, Y. X. Deng, L. Liu, Y. Liang, X. D. Liu, L. Xie, G. J. Wang and X. T. Wang, "A Sensitive and Specific Liquid Chromatography Mass Spectrometry Method for Simultaneous Determination of Berberine, Palmatine, Coptisine, Epiberberine and Jatrorrhizine from Coptidis rhizoma in Rat Plasma," International Journal of Mass Spectrometry, Vol. 268, No. 1, 2007, pp. 30-37. doi:10.1016/j.ijms.2007.08.003

[31] S. W. Sun and H. M. Tseng, "Sensitivity Improvement on Detection of Coptidis Alkaloids by Sweeping in Capillary Electrophoresis," Journal of Pharmaceutical and Biomedical Analysis, Vol. 37, No. 1, 2005, pp. 39-45. doi:10.1016/j.jpba.2004.09.042

[32] W. C. Chuang, D. S. Young, L. K. Liu and S. J. Sheu, "Liquid Chromatographic-Electrospray Mass Spectrometric Analysis of Coptidis rhizoma," Journal of Chromatography A, Vol. 755, No. 1, 1996, pp. 19-26. doi:10.1016/S0021-9673(96)00591-2
[33] Y. T. Deng, Q. F. Liao, S. H. Li, K. H. Bi, B. Y. Pan and Z. Y. Xie, Simultaneous Determination of Berberine, Palmatine and Jatrorrhizine by Liquid Chromatography-Tandem Mass Spectrometry in Rat Plasma and Its Application in a Pharmacokinetic Study after Oral Administration of Coptis-Evodia Herb Couple," Journal of Chromatography B, Vol. 863, No. 2, 2008, pp. 195-205. doi:10.1016/i.jchromb.2007.12.028

[34] H. L. Li, W. D. Zhang, R. H. Liu, C. Zhang, T. Han, X. W. Wang, X. L. Wang, J. B. Zhu and C. L. Chen, "Simultaneous Determination of Four Active Alkaloids from a Traditional Chinese Medicine Corydalis saxicola Bunting. (Yanhuanglian) in Plasma and Urine Samples by LC-MS-MS," Journal of Chromatography B, Vol. 831, No. 1-2, 2006, pp. 140-146. doi:10.1016/j.jchromb.2005.11.049

[35] H. S. Lee, Y. E. Eom and D. O. Eom, "Narrowbore High Performance Liquid Chromatography of Berberine and Palmatine in Crude Drugs and Pharmaceuticals with Ion-Pair Extraction Using Cobalt Thiocyanate Reagent," Journal of Pharmaceutical and Biomedical Analysis, Vol. 21, No. 1, 1999, pp. 59-63. doi:10.1016/S0731-7085(99)00113-2

[36] Y. X. Luo, D. X. Wen, S. J. Jiang, X. L. Zeng, J. N. Jiang, Y. C. Xu and P. D. Xie, "Studies on HPLC Fingerprint of Herba Corydalis Saxicolae," Chinese Journal of Pharmacutical Analysis, Vol. 27, No. 11, 2007, pp. 17491751.

[37] J. Y. Ling, G. Y. Zhang, Z. J. Cui and C. K. Zhang, "Supercritical Fluid Extraction of Quinolizidine Alkaloids from Sophora Flavescens Ait. and Purification by High-Speed Counter-Current Chromatography," Journal of Chromatography A, Vol. 1145, No. 1-2, 2007, pp. 123-127. doi:10.1016/j.chroma.2007.01.080

[38] F. Y. Yang and Y. Ito, "Preparative Separation of Lappaconitine, Ranaconitine, $N$-deacetyllappaconitine and $\mathrm{N}$-deacetylranaconitine from Crude Alkaloids of Sample Aconitum Sinomontanum Nakai by High-Speed CounterCurrent Chromatography," Journal of Chromatography A, Vol. 943, No. 2, 2002, pp. 219-225.

doi:10.1016/S0021-9673(01)01464-9 